\title{
WEB SERVICES FOR THE FOOTWEAR SECTOR IN A NETWORKED CONTEXT
}

\author{
Rosanna Fornasiero, Andrea Zangiacomi \\ \{r.fornasiero,a.zangiacomi\}@itia.cnr.it \\ Institute of Industrial Technologies and Automation - National Research Council., ITALY
}

\begin{abstract}
Manufacturing companies, in our case shoe producers, increasingly have the need to improve collaboration and co-operation across the company boarders. Especially in the case of SMEs they are more and more interested in building networks with the support of business integrators like trade associations or service providers which can guarantee qualified support. This paper describes a case study andpropose two different services in an Italianfootwear district to support shoe producers in managing automatically their temporary partnerships with suppliers and customers through ICT applications. The roles of the two service providers in the networking environment is compared.
\end{abstract}

\section{INTRODUCTION}

The raising use of ICT applications in the market has reached a relevant role for many enterprises. E-commerce seems to be useful especially in the Business to Business (B2B) giving the possibility to manage relationships among different companies in Virtual Enterprise (VE) context. Moreover, thanks to Internet solutions, also partnerships and agreements with suppliers or customers are easier to be signed and managed, hence many companies work in collaborative networks. Decreasing entry barriers have deeply affected this trend: actually also small firms, if in networks, can face the slighter costs that have to be paid to access virtual markets. On the other hand, e-commerce dissemination finds some hurdles, especially linked to the characteristics of enterprises and of sectors (Bianchi, Bottani, Simonella 2001).

Companies life is linked to the networking context in which they operate: in industrial districts complementary companies are located in a restricted area and take advantage of each other core business sharing competences in a collaborative environment. On the other hand looking at single company level, drawbacks like poor investment capability in ICT infrastructure can be found due to organizational limits because, for example, few personnel can be diverted from operational tasks. To integrate SMEs in industrial districts, service providers and associations are 
operative on the market offering services not only for bureaucratic activities (like administrative, legal, fiscal, etc) but also to support collaboration management through ICT tools.

The aim of this paper is to show through a case study how the configuration of collaborative networks can change and be eased thanks to the support of different kinds of business integrators like brokers, catalysts etc. which can have a different role in networking companies. Even the most advanced infrastructure coming out of some leading $R \& D$ projects sometimes require complex configuration and customization processes hardly manageable by SMEs (Camarinha-Matos, 2002) and for this reason business integrators are a solution.

\section{BACKGROUND}

The work of this paper is part of the EU project e-MMEDIATE (IST-2001-35104) which focus was on the implementation ICT-Tools to support SMEs in strengthening networks and easing VE configuration adapting to peculiarities of SMEs requirements. A general roadmap was proposed to provide a toolset and methodologies to support SMEs in the creation and management of VE for product development processes. Four different VEs in four different branches were selected to apply a common methodology to implement new workflows and to select appropriate ICT-Tools. Here only the Italian VE case in the footwear sector is described.

In literature various definitions of VE and virtual co-operations can be found in (Arnold et al., 1995), Bultje et al., 1998), (Camarinha-Matos et al., 1999) and others. For the purpose of this paper we use a definition of VE from (Bullinger et.al., 1995) where it is stated that "Virtual enterprises are temporarily horizontal and/or vertical location-spanning co-operations of independent companies with different degrees of autonomy". Sometimes collaboration is yield difficult due to problems of trust, integration of different software or organizational management of roles in the partnership. The methodology applied in the project is based on some useful methodologies to support industrial partners in defining their VE configuration and the specific requirements and is based on some suggestions given in (Bauer et al., 2003), (Chalmeta et al., 2003), (Wognum et al., 2002). The approach used in the project is a roadmap guiding any VE through the process of improving network management, especially through designing co-operation process and implementing ICT-Tools (e-MMEDIATE D8, 2003). It is important that the VE creation is done through configuration rather than through an ad hoc decision of procedures and rules or through new software design and implementation, because the objective is to be able to create and recreate efficient VEs in a very short time (Tølle et al., 2003).

The application of the roadmap was successful for all the VEs and guaranteed standard of quality in the working methods. Each VE followed a path in the implementation according to its own requirements. Periodic controls and comparison among the VEs have been useful and necessary to validate and for cross-fertilization. 


\section{CASE STUDY}

\subsection{Reference scenario}

The VE under consideration is peculiar in some characteristics: it is composed of a shoe producer and two service providers of the footwear sector collaborating to increase partnerships in an industrial district of shoe producers. The shoe producer designs, manufactures and distributes shoes. It is structured as an extended enterprise where each company is in charge of some productive phases but the company has also many temporary relationships with outsourcers (see below). One of the service providers is a trade association offering many different services to shoe producers from training to CAD co-design support, quality control and support on order management. The other service provider is a Laboratory for Design and Mass Customization (Lab) offering engineering consultancy services on automation systems, control systems and CAD/CAM support. Moreover at the Lab premises a fully automated and integrated plant is installed able to produce in a flexible and agile way mass customized shoes. This plant can be used to test (physically and virtually through simulation) new manufacturing technologies in the footwear sector.

The characteristics of the VE of the Italian cluster can be summarized as follows:

- Complete independence in the management of each of the three partners

- Distributed information and knowledge at each site

- The value creation of the VE takes place in each different location and each company provides core-competence for cooperative value creation.

- There is not yet a common platform for data exchange, only the trade association has a web portal which is partially used for knowledge sharing.

\subsection{Stock management service}

Shoes are fashion products with a short life cycle, therefore they are deeply linked to market trends which influence design aspects every season. Most of the time shoe producers are not interested in selling their products through an Internet site during the high season: the competitiveness is very strong and shoe design can be copied easily (Morlacchi et al., 1998). So the use of e-marketplace is not well spread especially among SMEs. Most of the time at the end of the season shoe producers have a certain amount of unsold shoes that they try to sell at the best price (most of the time even at lower price than the production costs) in order to get rid of stocks of shoes that can not be sold in the next season due to changes in fashion. This selling process is usually managed at the premises of the shoe producers with face-to-face meetings between seller and stock buyers. To speed up this process shoe producers feel the need to have an electronic system which support the online sales of stock. Since the unsold shoes are available at the end of the season there is no problem concerning confidentiality of the models and so the shoe producers have no problems in publishing information and/or pictures of the products on the web. 
After an analysis of the available software on the market it was decided that the best solution was to develop an ad-hoc web application, according to the collected requirements (Benedetti et al., 2003). As previously underlined, our specific case required to the software the possibility to sell whole or partial stock allowing the client to make free offers without the need to have an initial price defined by the seller. Moreover it is essential the protection of sensitive data concerning the customers and the prices under negotiation. Only some large shoe producers have already implemented their own online application for such a service. On the other hand the stock management here considered is not specific for just one shoe producer but can be used by many other company associated to the Trade Association making it available on their portal. In the future this tool could provide also an integration with the database of the different shoe producers in order to quickly retrieve the information which should be necessary for the stock sales.

In this context the Trade Association would like to improve and manage the relationship between shoe producers and dealers interested in buying unsold stocks. In their portal the Association already offers various services like training online, market trend studies, administrative laws notification and supplier management. According to the requirements coming from shoe producers a web-solution was designed in order to manage the stocks selling process. The association acts as a broker between suppliers and buyers: it administrates the service to guarantee sellers that only registered customers (whose references have to be previously controlled) have access to the purchasing procedures. Moreover, the Association receives a notification of stock offers, evaluates the content of the offers and then uploads them to the web site.

Hence the portal is the way by which the shoe manufacturers and potential customers interested in buying unsold stocks can meet easier than with face-to-face meetings. Potential customers can check the on-line stocks catalogue and make offers to buy stocks (partially or totally). In particular they can also make an offer regarding different stocks. The shoe producer can find customers that would buy a set of products they have chosen in a quicker and easier way.

The system implemented and tested with some shoe producers is so structured:

- Web interface which provides data and information at the client level

- Web server and application which manage data and information installed at the trade association premises

The service is accessible through internet and a browser like IE or Netscape.

Usually shoe producers do not have enough internal resources (competences and money) to implement such a system and they would go on working on traditional way. The service gives them the possibility to create many new temporary VEs with dealers and other shoe producers giving more visibility to the company which can use the portal to sell unsold stocks and to do web marketing. Moreover the relationships become more secure because the association can guarantee a control on the companies accessing the system to buy online.

\subsection{Simulation and cost evaluation service}

From the point of view of shoe production, the value chains are composed of many different actors which are involved at different stages of the process. Usually the shoe producer deals mainly with the final phase of the manufacturing cycle (called 
making phase) which is the most crucial one and consists in assembling shoe components like uppers, heels, soles and insoles. Previous steps as the cutting of the leather and the upper stitching are often outsourced to other small enterprise specialized in this kind of operations. Anyway most of the firms outsource partially or totally even the final shoe assembly. This implies a trusty relationship between shoe producers and outsourcers in order to guarantee the necessary quality level at the proper cost.

Shoe production is very variable along the time horizon because it is linked to seasonal sales. This leads to an increase in the complexity of planning activity in order to fill and level the available internal and external capacity. Shoe producers are mainly SMEs and their planning capability depends on the experience and competence of the production manager who has to deal with shop floor activity and outsourcing plans according to an increasing variability of the market demand.

Nowadays the process of selection and evaluation of outsourcers is based on direct contacts with well-known partners and make or buy decisions are taken without any support systems. In order to manage and evaluate different outsourcing solutions in a scientific way it was thought to develop an electronic system which support the online evaluation of the performance of different outsourcers.

The service developed in the Lab provide shoe producers with an evaluation system based on the simulation of seasonal production plans. Cost evaluation analysis integrated with simulation gives a suitable and easily readable results for companies (Spedding et al., 1999), (Andrade et al., 1999). Simulation based on discrete events can give good forecasts of the production planning and can be integrated with a production costs evaluation for new assembling lines or for new product range (see Avai et al., 1999; Boer et al. 1993).

The service developed and tested allow a shoe producer to select the simulation models on which he wants to run his orders and insert data and information on the production mix. Deploying this service a shoe producer can simulate its own production process, production process of the outsourcers in order to take make or buy decisions and production process of the integrated plant in the Lab to test innovative technologies on its own production.

The web application runs simulations on the order data provided by the shoe producer, and calculates the process and product costs according to the model cost selected. The development of such a kind of services was based on the following steps:

- development of web interface to provide data and information at client level

- installation of web server and application server at the Lab premises

- structuring database for data provision

- development of simulation models and costing models with the shoe producer

The user can access to the service using a common browser like Internet Explorer or Netscape. The real production processes are simulated with Arena to visualize the layout peculiarities like time lag between an operation and the other, number of people at each phase, number and time for setup, etc. 
The output data of the simulation model (time, number of shoes produced, number of scraps) are input for the costing model. The hardware architecture is given in the following figure.

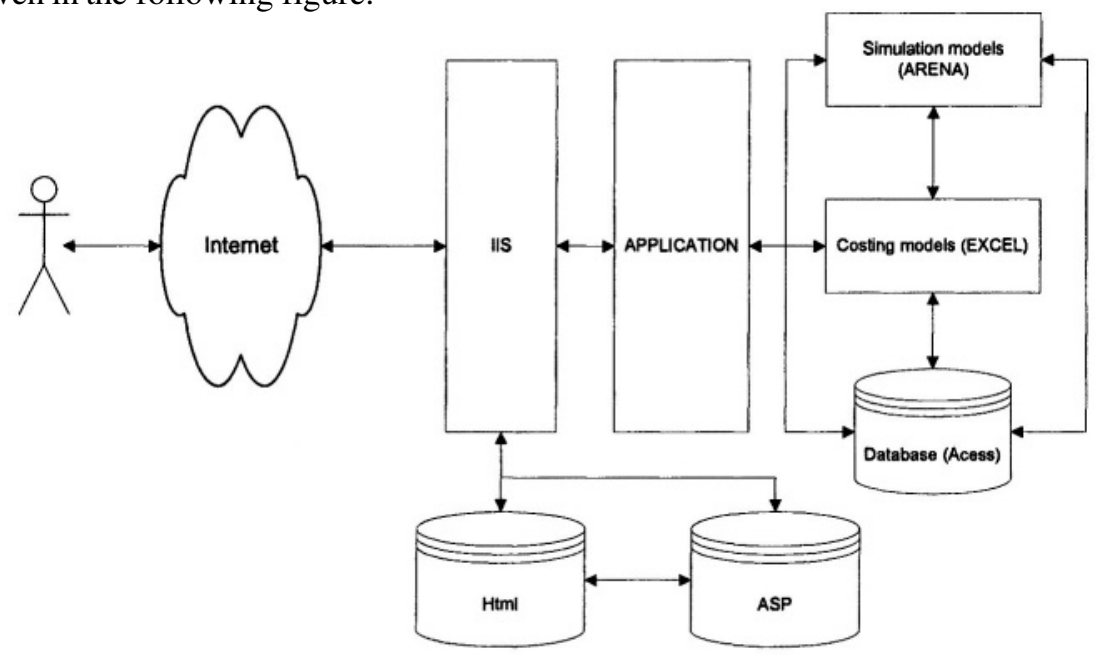

Fig.1: Hardware Architecture

As came out from the real implementation of the service this kind of application implies a deeper involvement of the service provider respect to the stock management previously described: every time a member is registered to the system it is necessary to collect all the data and information about its production process and costing system to make available the new model on the web. The service is a decision support tool; the effort required when entering for the first time the system is much higher but then the shoe producers can easily and quickly evaluate how different orders can be produced in different production plants.

\section{CONCLUSIONS}

The support of a business integrator guarantees merging of a pool of interests and competencies not available in a single SME and assures to reach a critical size to be in accordance with market constraints. Moreover optimization of the processes is easier as the case of cost evaluation through simulation shows.

Most of the time SMEs are in a context which can be called "breeding environment" for dynamic formation of VE (Camarinha-Matos, 2003). Regional districts where many companies of the same sector are concentrated can be considered a breeding environment where associations and service providers support cooperation agreements with common infrastructures. When one of the SMEs finds a business opportunity, a subset of all companies may form a VE for that specific opportunity with the support of a broker. The new partners entering in a dynamic way in the VE join the common infrastructure and cooperation principles.

Looking at the services described in this paper, we can underline two different roles in service provision. The trade association is just providing a service (stock management) with a function of controlling operations, checking reliability of 
potential customers and validating offers. On the other side the Lab actively customize the service for each shoe producer since the specific production process has to be drawn with them and a costing model adapted according to their accounting system.

Several VEs can co-exist at the same time within the breeding environment even with some members in common. In fact the environment in not a closed one: new members can adhere to a certain service but they have to comply with the general operating principles of the broker. The establishment and management of the VE through adequate infrastructures represent therefore an important support for the creation of agile partnerships.

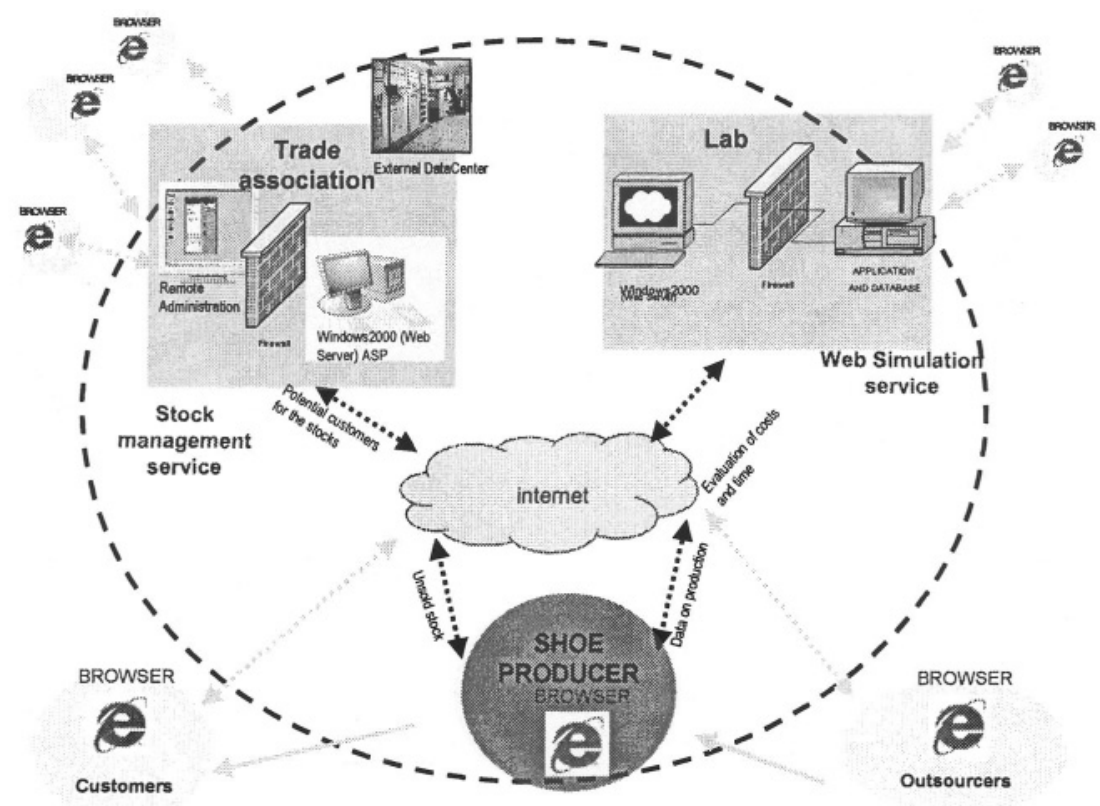

Figure 2: Overall architectural design

The two different solutions implemented and tested at prototype level in this VE are focused on the idea of creating a set of tools to support and promote the extension of the VE for SMEs both from the side of suppliers (simulation service) and customers (stock management service). To undertake this aim the IT tools implemented do not force the VE towards a rigid and closed structure but on the contrary offer new collaboration opportunities widening the vision on a common cooperation scenario. 


\section{ACKNOWLEDGEMENTS}

This paper has been partially conducted thanks to the support of the IST project No. IST-2001-35104: e-MMEDIATE, "electronic Managing of product Manufacturing, Engineering, Design and Investment Applying information Technology for SMEs ".

\section{REFERENCES}

1. Andrade M.C.,. Pessanha Filho R.C., Espozel A.M., Maia L.O.A., Qassim R.Y., “Activity-Based Costing for production learning", International Journal of Production Economics, 1999.

2. Arnold O, Faisst W, Härtling M, Sieber P.(1995): Virtuelle Unternehmen als Unternehmenstyp der Zukunft? published in:: HMD, Nr. 185, p. 8-23

3. Avai, S. Dulio, M. Sacco, C.R. Boër, "Agile, one pair shoe production system: The role of simulation as a design tool for the manufacturing system and virtual reality for the design of the shoe, Cenim Workshop, May 1999

4. Bauer R., Koszegi S.T. (2003): Measuring the degree if virtualization, published in electronic Journal of Organizational Virtualness 5, 26-46.

5. Benedetti L., Carotenuto P., Fornasiero R., Zangiacomi A.: Approaching B2B for SMEs in the footwear sector. Proceeding of the International Symposium of Logistics 2003 "Logistics and the Digital Economy”, K.S.Pawar and M.Muffatto eds.

6. Bianchi, Bottani, Simonella (2001) "Electronic commerce business impact project: Textile-clothing sector in Italy" in OECD EBIP PROJECT.

7. Boër C.R., Avai A., Imperio E., El-Chaar J. "Computer simulation for the design and planning of flexible assembly systems", International workshop on "Application and development of modeling and simulation of manufacturing systems"; Beijing, 1993, pp. 84-98

8. Bullinger, H.J.; Brettreich-Teichmann, Fröschle, H.P. (1995): Das virtuelle Unternehmen Koordination zwi-schen Markt und Hierarchie, published in: Office Management 43, p. 18-22.

9. Bultje R., van Wijk, J. (1998): Taxonomy of Virtual Organisations, based on definitions, characteristics and typology., Published in: VoNet: The Netwsletter @ http://www.virtualorganization.net/, p. 9.

10. Camarinha-Matos L.M., Afsarmanesh H. Eds. (1999): Infrastructures for Virtual Enterprises Networking Industrial Enterprises, Kluwer Acedemic Publishers. Dorchecht, 1999. ISBN 0-79238639-6

11. Camarinha-Matos L.M., Afsarmanesh H. (2002): Dynamic Virtual Organizations, or Not So Dynamic? In Marík V., Camarinha-Matos L.M., Afsarmanesh H. (Eds.): Proceedings of International Conference on Information Technology for Balanced Automation Systems in Manufacturing and Services (BASYS'02), IFIP 229 Kluwer .111-124

12. Camarinha-Matos L.M., Afsarmanesh H. (2003): Elements of a base VE infrastrcuture. Computers in Industry, vol. 51 pp. 139-163

13. Chalmeta R., Grangel R. (2003): ARDIN extension for virtual enterprise integration. Journal of Systems and Software, vol. 67 pp. 141-152

14. e-MMEDIATE Project Consortium (2003): D8: Final Dissemination kit Project document of European pro-ject e-MMEDIATE(IST-2001-35104); Brussels.

15. Morlacchi, G. Bellotti, F. Gambino, "L'impresa calzaturiera: progettazione tecnica e organizzazione" Vol. III - Editrice s.r.1. 1998

16. Spedding T.A., Sun G.Q., "Application of discrete event simulation to the Activity Based Costing of manufacturing system”, International Journal of Production Economics, 1999.

17. Tolle M., Bernus P. (2003): Reference models supporting enterprise networks and virtual enterprises in International Jounrla of Networking and Virtual Organizations, vol. 2-1 pp.2-15

18. Wognum P.M., Faber E.C.C.: Infrastructures for collaboration in virtual organizations, International Journal of Networking and Virtual Organizations, vol.1-1, pp.32-54 